09

\title{
Генерация терагерцевого излучения с поверхности монослойного $\mathrm{WSe}_{2}$
}

\author{
() А.В. Горбатова, Д.И. Хусяинов, А.М. Буряков \\ МИРЭА - Российский технологический университет, Москва, Россия \\ E-mail: gorbatova.anastasiya@mail.ru
}

Поступило в Редакцию 12 сентября 2019г.

В окончательной редакции 12 сентября 2019 г.

Принято к публикации 20 сентября 2019 г.

\begin{abstract}
Впервые исследованы параметры генерации терагерцевого излучения в двумерной пленке WSe 2 , выращенной методом химического осаждения из газовой фазы. Определен основной механизм генерации терагерцевого излучения в рассматриваемой структуре. Исследована зависимость амплитуды терагерцевого сигнала от азимутального угла двумерной пленки $\mathrm{WSe}_{2}$. Проведен расчет распределения электрического поля лазерной накачки в структуре $\mathrm{WSe} 2 / \mathrm{SiO}_{2} / \mathrm{Si}$ в зависимости от толщины диоксида кремния. Теоретически обоснован выбор оптимальной геометрии структуры для эффективной генерации терагерцевого излучения монослойной пленкой $\mathrm{WSe}_{2}$.
\end{abstract}

Ключевые слова: двумерные полупроводники, дихалькогениды переходных металлов, диселенид вольфрама $\left(\mathrm{WSe}_{2}\right)$, терагерцевая эмиссия, оптическое выпрямление.

DOI: 10.21883/PJTF.2019.24.48803.18032

Возможность генерации терагерцевого (THz) излучения в графене впервые была показана в работах $[1,2]$. Однако отсутствие запрещенной зоны в графене существенно ограничивает его дальнейшее применение в качестве фотопроводящего материала терагерцевых антенн. Данная проблема была решена с появлением новых двумерных слоистых материалов - дихалькогенидов переходных металлов (ДПМ). Монослои ДПМ характеризуются прямой запрещенной зоной с энергией в видимой области спектра, благодаря чему могут найти применение в устройствах фотоники и оптоэлектроники [3-5]. В ряде работ была продемонстрирована возможность генерации THz-излучения с поверхности объемных слоистых ДПМ, таких как $\mathrm{MoS}_{2}$ и $\mathrm{WS}_{2}$ [6,7]. Исследование двумерных пленок ДПМ, созданных методом химического осаждения из газовой фазы (ХОГФ), является перспективным, поскольку планарная технология - основной метод создания электронных устройств [8]. Монослойный $\mathrm{WSe}_{2}$ - один из наиболее перспективных ДПМ, он характеризуется относительно большой подвижностью носителей зарядов $\left(202 \mathrm{~cm}^{2} /(\mathrm{V} \cdot \mathrm{s})\right.$ для электронов и $250 \mathrm{~cm}^{2} /(\mathrm{V} \cdot \mathrm{s})$ для дырок) и малым временем жизни носителей заряда (1 ps), а также узкой запрещенной зоной $(1.62 \mathrm{eV})$ по сравнению с другими монослоями ДПМ [9-11], что является важным фактором при создании $\mathrm{THz}-$-стройств. В настоящей работе методом THz-спектроскопии временно́го разрешения исследовались и анализировались параметры (ширина спектра, амплитуда, анизотропия амплитуды, эффективность поглощения) THz-импульсов, генерируемых с поверхности двумерной пленки $\mathrm{WSe}_{2}$.

Двумерная пленка $\mathrm{WSe}_{2}$ была выращена методом ХОГФ на подложке $\mathrm{SiO}_{2} / \mathrm{Si}$ с толщиной диоксида кремния $\left(\mathrm{SiO}_{2}\right) 285 \mathrm{~nm}$. Данный образец имеет стандартную толщину $\mathrm{SiO}_{2}$, дающую оптимальный контраст оптического изображения между пленкой и подложкой. Двумерная пленка $\mathrm{WSe}_{2}$ была предварительно исследована методом атомно-силовой микроскопии (АCM). Изображение топографии исследуемой структуры и сечение представлены на рис. 1. В соответствии с полученными результатами толщина пленки составляет $\sim 1 \mathrm{~nm}$.

Исследование параметров генерации THz-излучения с поверхности двумерной пленки $\mathrm{WSe}_{2}$ проводилось методом THz-спектроскопии временно́го разрешения в геометрии на отражение. В качестве источника фемтосекундного лазерного излучения использовался лазер Mai-Tai Spectra-Physics с длительностью импульсов $100 \mathrm{fs}$ и частотой следования импульсов $82 \mathrm{MHz}$. Оптический луч накачки падал на поверхность образца под углом $45^{\circ}$. Лазерный луч не фокусировался на поверхности пленки для увеличения площади взаимодействия, поскольку монослой $\mathrm{WSe}_{2}$ является достаточно прозрачным для электромагнитного излучения. Плотность энергии луча накачки составляла $\sim 0.5 \mu \mathrm{J} / \mathrm{cm}^{2}$.

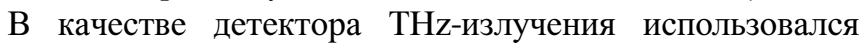
нелинейно-оптический кристалл ZnTe.

$\mathrm{B}$ ходе исследования пленки $\mathrm{WSe}_{2}$ методом терагерцевой спектроскопии временно́го разрешения были получены временны́е формы THz-импульсов. Частотный спектр THz-излучения был получен методом фурьепреобразования волновой формы THz-сигнала, он представлен на рис. 2, $a$. Далее проводилась оценка эффективности генерации THz-излучения в монослойном $\mathrm{WSe}_{2}$ и эталонном образце $\mathrm{In}_{0.53} \mathrm{Ga}_{0.47} \mathrm{As}$. Твердый раствор $\mathrm{In}_{0.53} \mathrm{Ga}_{0.47} \mathrm{As}$ - довольно хорошо изученный и часто используемый материал для создания коммерческих фотопроводящих антенн. Амплитуда THz-сигнала в $\mathrm{WSe}_{2}$ нормирована на объем полного поглощения 

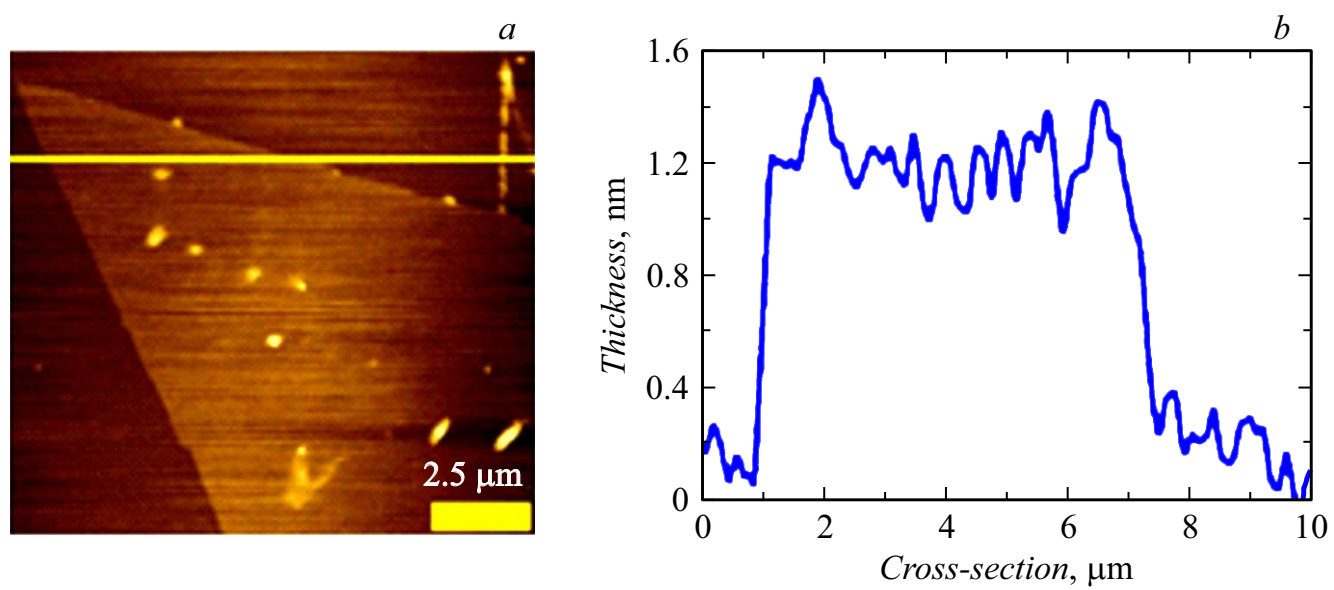

Рис. 1. Топография двумерной пленки $\mathrm{WSe}_{2}(a)$ и ее сечение $(b)$, полученные методом АCM.

оптического излучения в $\mathrm{In}_{0.53} \mathrm{Ga}_{0.47} \mathrm{As}$ в соответствии с законом Бугера-Ламберта-Бера (рис. 2, a). С учетом нормировки было получено, что эффективность генерации THz-излучения в монослойном полупроводнике $\mathrm{WSe}_{2}$ в 2 раза выше, чем в $\mathrm{In}_{0.53} \mathrm{Ga}_{0.47} \mathrm{As}$. Двумерная

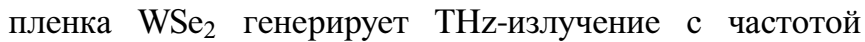
до $3.2 \mathrm{THz}$. Пик амплитуды THz-сигнала соответствует частоте $0.6 \mathrm{THz}$.

Ширина запрещенной зоны монослойного $\mathrm{WSe}_{2}$ соответствует $1.62 \mathrm{eV}$ [9]. При этом энергия лазерного излучения накачки составляла $1.55 \mathrm{eV}$. Следовательно, энергии фотона оптического излучения недостаточно для перехода электронов в исследуемой полупроводниковой структуре из валентной зоны в зону проводимости. Очевидно, что вклад в THz-генерацию поверхностного поля и фотоэффекта Дембера можно исключить ввиду отсутствия поглощения оптического излучения. Можно заключить, что в двумерной пленке $\mathrm{WSe}_{2}$ генерация THz-излучения связана с нелинейно-оптическим эффектом второго порядка - оптическим выпрямлением. Эффект оптического выпрямления ярко выражен в материалах с высокими значениями нелинейной восприимчивости второго порядка $\chi^{(2)}$. При этом амплитуда THz-излучения будет зависеть от азимутального угла кристаллической структуры. Результаты исследования зависимости амплитуды генерируемого THz-сигнала от азимутального угла $\mathrm{WSe}_{2}$ представлены на рис. 2, $b$.

$\mathrm{B}$ общем случае для кристаллитов $\mathrm{WSe}_{2}$ возможны три точечные группы симметрии. Для центросимметричного $2 H$-политипа группа точечной симметрии $D_{6 h}^{4}\left(P 6_{3} / m m c\right)$. При этом симметрия $\mathrm{WSe}_{2}$ различается в зависимости от четности или нечетности количества слоев. Для нечетного числа слоев, в том числе и для монослоя, точечная группа симметрии имеет вид $D_{3 h}^{1}(P 6 m 2)$. Для четного числа слоев точечная группа симметрии имеет вид $D_{3 d}^{1}(P 3 m 1)$. Поскольку точечная группа $D_{3 h}^{1}$ является нецентросимметричной, нелинейно-оптический сигнал в монослойном $\mathrm{WSe}_{2}$ в основном будет обеспечен электродипольным вкла- дом [12]. В соответствии с этим утверждением соотношение между электрическим полем световой волны $E(\omega)$ и индуцируемой нелинейной поляризацией на разностной частоте $P^{(2)}(0)$ можно записать следующим образом:

$$
P_{i}^{(2)}(0)=\sum_{j, k} \varepsilon_{0} \chi_{i j k}^{(2)}(0, \omega,-\omega) E_{j}(\omega) E_{k}^{*}(\omega)
$$

Далее для расчета нелинейной поляризации определены независимые ненулевые компоненты тензора нелинейной восприимчивости второго порядка в соответствии с симметрией двумерной пленки $\mathrm{WSe}_{2}$. Для данного случая симметрии возможен лишь один независимый ненулевой компонент тензоpa: $\chi^{(2)}=\chi_{y y y}=-\chi_{y x x}=-\chi_{x x y}=-\chi_{x y x}$. Анализ полученной азимутальной зависимости для монослойного $\mathrm{WSe}_{2}$ проводился в соответствии с соотношением (1). Кристаллографический срез монослоя был определен как (001). Результат расчета зависимости THz-поля от азимутального угла кристаллической структуры для нецентросимметричного монослоя $\mathrm{WSe}_{2}$ в геометрии $p$-анализатора можно записать в виде

$$
E^{(\mathrm{THz})} \propto \chi_{y y y} \cos (3 \varphi),
$$

где $\varphi$ - азимутальный угол. Аппроксимация экспериментальных результатов с помощью формулы (2) приведена на рис. 2, $b$ (Fitting $D_{3 h}^{1}$ ). Очевидно несоответствие между экспериментально полученной зависимостью и моделью, описываемой формулой (2). Как было показано в работах $[13,14]$, отдельные кристаллиты $\mathrm{WSe}_{2}$ в процессе роста ориентируются под разными углами относительно друг друга. Поскольку THz-излучение генерируется с поверхности пленки площадью $\sim 0.8 \mathrm{~mm}^{2}$, можно утверждать, что в генерации участвуют кристаллиты, ориентированные в разных направлениях (от 0 до $2 \pi$ ). Поэтому итоговое значение генерируемого THz-поля будет определяться в соответствии 


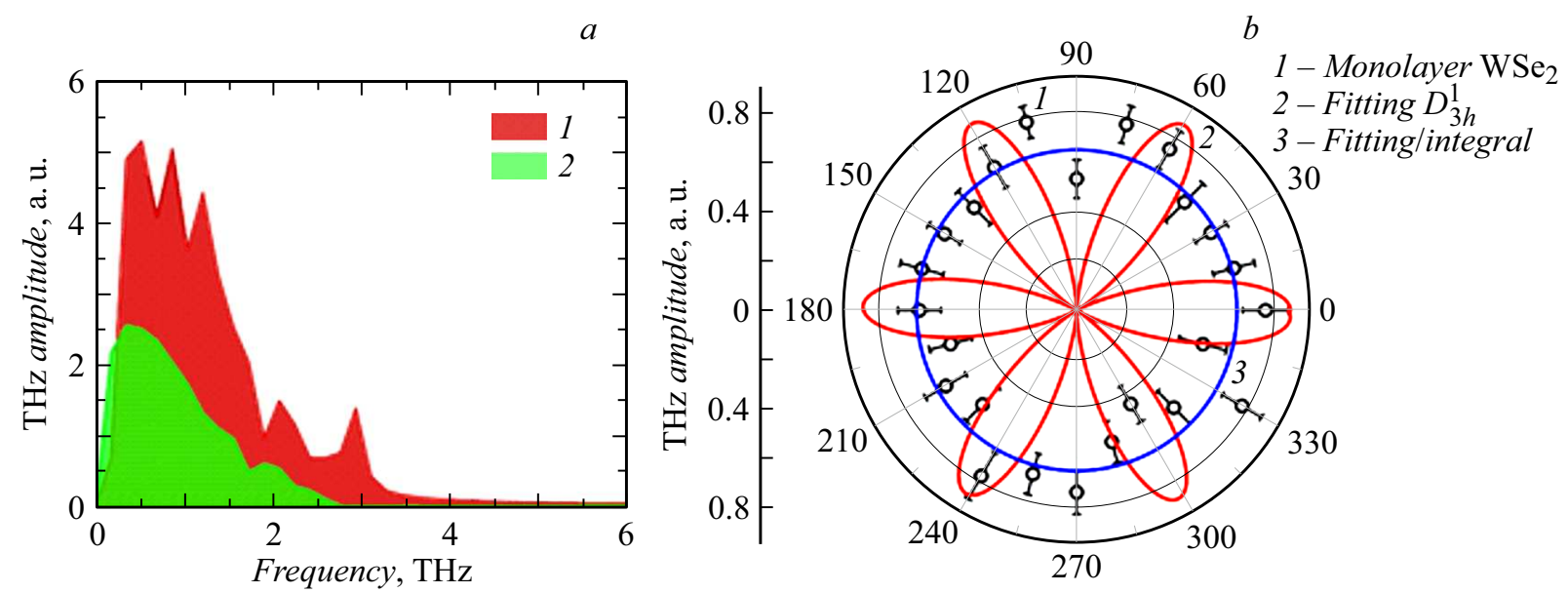

Рис. 2. $a$ - частотные спектры THz-импульсов, генерируемых монослойным $\mathrm{WSe}_{2}(1)$ и $\operatorname{In}_{0.53} \mathrm{Ga}_{0.47} \mathrm{As}(2)$. $b$ - азимутальная угловая зависимость амплитуды THz-излучения в монослое $\mathrm{WSe}_{2}$.
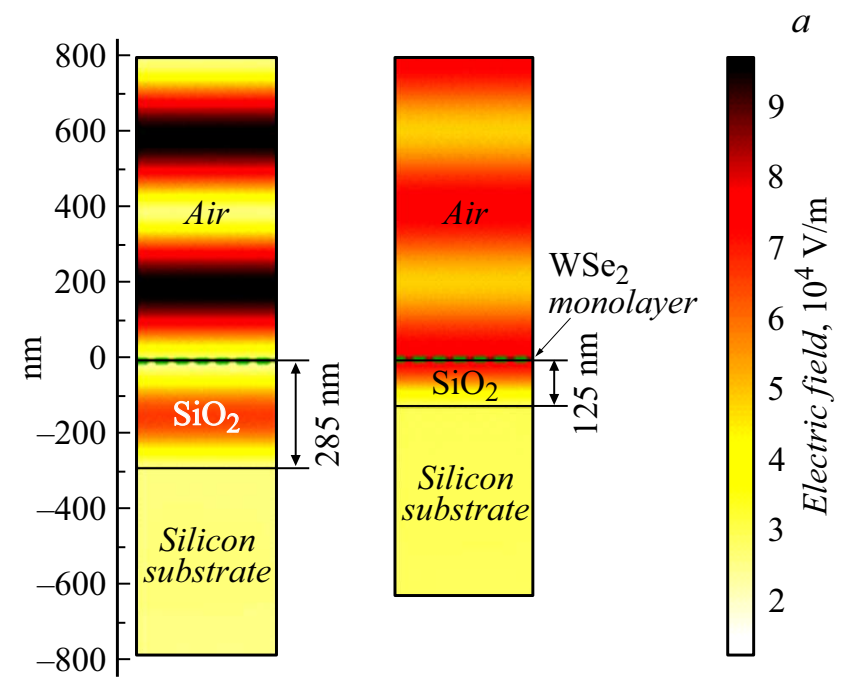

$b$

Рис. 3. $a$ - распределение электрического поля лазерной накачки в системе воздух $/ \mathrm{WSe}_{2} / \mathrm{SiO}_{2} / \mathrm{Si}$ на длине волны $800 \mathrm{~nm}$ для толщин диоксида кремния $285 \mathrm{~nm}$ (слева) и $125 \mathrm{~nm}$ (справа). $b$ - зависимость напряженности электрического поля в монослое $\mathrm{WSe}_{2}$ от толщины $\mathrm{SiO}_{2}$.

с выражением

$$
E_{\text {total }}^{(\mathrm{THz})} \propto \int_{0}^{2 \pi} \chi_{y y y} \cos (3 \varphi) d \varphi .
$$

В результате значение THz-поля будет определяться лишь значением независимого ненулевого компонента тензора $\chi_{y y y}$ (рис. 2, b, Fitting/integral). Таким образом, можно утверждать, что единственно возможным механизмом генерации THz-излучения является оптическое выпрямление.

Далее было рассчитано распределение электрического поля лазерной накачки в двумерной пленке $\mathrm{WSe}_{2}$. Структура $\mathrm{WSe}_{2} / \mathrm{SiO}_{2} / \mathrm{Si}$ может работать как резонатор Фабри-Перо при определенных интерференционных условиях, что может служить дополнительным инструментом увеличения эффективности генерируемого THz-поля. Толщина диоксида кремния оказывает сильное влияние на распределение электромагнитного результирующего поля лазерной накачки в двумерной пленке $\mathrm{WSe}_{2}$. C помощью программной среды COMSOL Multiphisics было промоделировано распределение электромагнитной волны $(\lambda=800 \mathrm{~nm})$ в структуре $\mathrm{WSe}_{2} / \mathrm{SiO}_{2} / \mathrm{Si}$. В рамках поставленной задачи была создана двумерная модель исследуемой системы. Коэффициенты преломления $(n)$ и поглощения $(k)$ для $\mathrm{WSe}_{2}, \mathrm{SiO}_{2}$ и $\mathrm{Si}$ были взяты из литературных источников [15-17]. Полученные распределения электрического поля оптической накачки в системе воздух $/ \mathrm{WSe}_{2} / \mathrm{SiO}_{2} / \mathrm{Si}$ для толщин диоксида кремния 285 и $125 \mathrm{~nm}$ приведены на рис. 3,a. На рис. 3, $b$ представлена зависимость напряженности электрического поля волны в моно- 
слойном $\mathrm{WSe}_{2}$ от толщины $\mathrm{SiO}_{2}$. Максимальное значение напряженности электрического поля в структуре $\mathrm{WSe}_{2} / \mathrm{SiO}_{2} / \mathrm{Si}$ наблюдается для толщин диоксида кремния 125 и $400 \mathrm{~nm}$. Из этого можно сделать вывод, что максимальное поглощение падающего лазерного излучения будет достигаться при указанных толщинах $\mathrm{SiO}_{2}$, при этом эффективность THz-генерации теоретически может быть увеличена в 3 раза.

В заключение отметим, что мы наблюдали ТНz-эмиссию с поверхности двумерной пленки $\mathrm{WSe}_{2}$ и показали, что монослой генерирует $\mathrm{THz}-$ сигнал с частотой до $3.2 \mathrm{THz}$. Симметрийный анализ азимутальной зависимости THz-амплитуды показал, что основным вкладом в генерацию THz-излучения является механизм оптического выпрямления. Теоретически обосновано, что эффективность $\mathrm{THz}$-генерации в монослойном $\mathrm{WSe}_{2}$ может быть увеличена в 3 раза при использовании оптимальной толщины диоксида кремния $125 \mathrm{~nm}$.

\section{Финансирование работы}

Исследование выполнено при финансовой поддержке Российского научного фонда (проект № 19-72-10165). Работы по созданию экспериментальной установки и отработке методики выполнены при финансовой поддержке Министерства образования и науки РФ (государственное задание № 3.7331.2017/9.10 (А.М. Буряков)).

\section{Конфликт интересов}

Авторы заявляют, что у них нет конфликта интересов.

\section{Список литературы}

[1] Bahk Y.-M., Ramakrishnan G., Choi J., Song H., Choi G., Kim Y.H., Ahn K.J., Kim D.-S., Planken P.C.M. // ACS Nano. 2014. V. 8. N 9. P. 9089-9096.

[2] Maysonnave J., Huppert S., Wang F., Maero S., Berger C., de Heer W., Norris T.B., De Vaulchier L.A., Dhillon S., Tignon J., Ferreira R., Mangeney J. // Nano Lett. 2014. V. 14, N 10. P. 5797-5802.

[3] Tian H., Chin M.L., Najmaei S., Guo Q., Xia F., Wang H., Dubey M. // Nano Res. 2016. V. 9. N 6. P. 1543-1560.

[4] Брехов К.А., Гришунин К.А., Ильин Н.А., Шестакова А.П., Лавров С.Д., Мишина Е.Д. // Письма в ЖТФ. 2017. Т. 43. B. 24. C. $46-52$.

[5] Авдижиян А.Ю., Лавров С.Д., Кудрявцев А.В., Шестакова А.П., Васина М.В. // Письма в ЖТФ. 2019. Т. 45. В. 12. C. $42-44$.

[6] Huang Y., Zhu L., Zhao Q., Guo Y., Ren Z., Bai J., Xu X. // ACS Appl. Mater. Interfaces. 2017. V. 9. N 5. P. 4956-4965.

[7] Zhang L., Huang Y., Zhao Q., Zhu L., Yao Z., Zhou Y., Du W., $X u$ X. // Phys. Rev. B. 2017. V. 96. N 15. P. 155202.

[8] Лавров С.Д., Шестакова А.П., Авдижиян А.Ю., Мишина Е.Д. // Письма в ЖТФ. 2018. Т. 44. В. 22. С. 19-24.

[9] Kumar A., Ahluwalia P.K. // Eur. Phys. J. B. 2012. V. 85. N 6. P. 186.

[10] Fang H., Chuang S., Chang T.C., Takei K., Takahashi T., Javey A. // Nano Lett. 2012. V. 12. N 7. P. 3788-3792.
[11] Docherty C.J., Parkinson P., Joyce H.J., Chiu M.-H., Chen C.-H., Lee M.-Y., Li L.-J., Herz L.M., Johnston M.B. // ACS Nano. 2014. V. 8. N 11. P. 11147-11153.

[12] Буряков А.М. // Рос. технологический журнал. 2017. Т. 5. № 2. C. 22-31.

[13] Stehle Y., Meyer H.M., Unocic R.R., Kidder M., Polizos G., Datskos P.G., Jackson R., Smirnov S.N., Vlassiouk I.V. // Chem. Mater. 2015. V. 27. N 23. P. 8041-8047.

[14] Ghasemi F., Frisenda R., Dumcenco D., Kis A., Perez de Lara D., Castellanos-Gomez A. // Electronics. 2017. V. 6. N 2. P. 28.

[15] Liu H.-L., Shen C.-C., Su S.-H., Hsu C.-L., Li M.-Y., Li L.-J. // Appl. Phys. Lett. 2014. V. 105. N 20. P. 201905.

[16] Tan C.Z. // J. Non. Cryst. Solids. 1998. V. 223. N 1-2. P. 158 163.

[17] Malitson I.H. // J. Opt. Soc. Am. 1965. V. 55. N 10. P. 12051209. 